\title{
Bone marrow micrometastasis in breast cancer: review of detection methods, prognostic impact and biological issues
}

\author{
A Vincent-Salomon, F C Bidard, J Y Pierga
}

Institut Curie, Paris, France

Correspondence to: Dr A Vincent-Salomon, Department of Pathology, Institut Curie, 26 rue d'Ulm 75248 Paris Cedex 05, France; anne.salomon@curie.net

Accepted 8 November 2007 Published Online First 23 November 2007

\begin{abstract}
Immunocytochemical detection of disseminated tumour cells in the bone marrow of patients with primary breast cancer at surgery has been shown to be an independent prognostic factor in single institutional studies and in a large pooled analysis. However, bone marrow sampling and assessment of disseminated tumour cells is not a routine procedure in the clinical management of patients with breast cancer, but will certainly play a role in the near future for risk stratification and monitoring of therapeutic efficacy. Accurate identification of disseminated tumour cells in bone marrow must be based on standardised methodologies and procedures. This review describes these methodologies and the standardised morphological criteria used for disseminated tumour cell detection. The prognostic value of circulating tumour cells detection in peripheral blood is demonstrated in patients with metastatic disease but remains to be substantiated at early stage. The significance of disseminated tumour cells in bone marrow and in the blood for the prediction of response to therapy is briefly summarised. Finally, this review addresses the main biological questions raised by disseminated tumour cells, in particular understanding tumour dormancy and identifying metastatic stem cells.
\end{abstract}

In clinical practice, the most important prognostic information about breast cancer is provided by pathological staging, such as tumour grade, tumour size, presence of lymphatic and vascular invasion, axillary lymph node involvement and steroid receptor status. Nonetheless, about $20-30 \%$ of patients with a favourable prognosis relapse within 5 years and many patients with poor prognostic factors will survive for more than 10 years. In this context, there is a real need for new, more accurate prognostic factors. One of the promising new parameters is identification of the presence of disseminated tumour cells (DTC) in bone marrow (BM). DTC, the most precise term, are also described by several synonyms such as bone marrow micrometastasis or minimal residual disease. The presence of BM DTC is clearly associated with a poor outcome for patients with stage I to III breast cancer. ${ }^{1}$ The procedure is still investigational according to the American Society of Clinical Oncology 2007 update of recommendations for the use of tumour markers in breast cancer, ${ }^{2}$ and its incorporation into clinical management algorithms is currently the focus of research. Many different methodologies have been used to detect DTC, but standardised guidelines have now been published. ${ }^{3}$ The current challenge for pathologists is to improve and standardise early detection of DTC. In this review, we will summarise the methodologies most commonly used to detect DTC, discuss the clinical impact of DTC in bone marrow at initial diagnosis and during follow-up and treatment evaluation, and highlight the biological and clinical questions raised by DTC.

\section{METHODOLOGIES FOR DETECTION OF BONE MARROW MICROMETASTASES}

The methodology most commonly used to detect DTC is immunocytochemistry performed on BM aspirates. Immunocytochemistry currently remains the gold standard for BM DTC detection, with a sensitivity ranging from 1 DTC in $10^{5}$ to 1 in $10^{6}$ leucocytes.

\section{Bone marrow aspiration}

Ideally, this procedure should be performed under general anaesthesia, at the time of initial surgery, before the skin incision. If necessary, it can be performed under local anaesthesia. Bone marrow aspirates are usually performed from both anterior iliac crests, as no difference has been reported between anterior and posterior iliac crest aspirations. ${ }^{4}$ Bone marrow (5-10 ml) should be aspirated and pooled in heparinised tubes, EDTA or sodium citrate until further processing. Optimal storage temperature is at $4-25^{\circ} \mathrm{C}$. A Ficoll density gradient centrifugation for tumour cell enrichment is performed, ideally within the first 24 hours after collection. A cell count is performed on the interphase layer containing mononuclear cells, and cytospins are prepared and smeared on positively charged glass slides; $2-3 \times 10^{6}$ cells per patient are examined. The slides (3-6 slides per patient) are air-dried at $4^{\circ} \mathrm{C}$ or at room temperature overnight before fixation ${ }^{3}$ and immunostaining.

\section{Immunocytostaining \\ Antibodies}

The majority of studies use the fact that breast cancer is an epithelial cell tumour and that BM normally does not contain any epithelial cells. Various antibodies have been used over the years: initially polyclonal antibodies raised against epithelial membrane antigen (EMA), which was subsequently abandoned as this antibody can cross-react with plasma cells and immature precursors in bone marrow; then monoclonal antibodies raised against various cytokeratins, mucins (MUC1), mammaglobin and adhesion molecules such as EpCAM. The most commonly used antibody at the present time is A45/BB3 (Micromet, Munich, Germany), a online under the BMJ Journals unlocked scheme, see http:// jcp.bmj.com/info/unlocked.dt 
monoclonal antibody that reacts with common epitopes on several cytokeratins including CK8, CK18 and CK19. Other antibodies include CK2 (mouse IgG1, Boehringer, Mannheim) directed against CK18, and AE1/AE3 that reacts with basic and acidic keratins covering a large spectrum of cytokeratins (CK10, CK14-16, CK19 and CK1-8). The recommended revelation system is the alkaline-anti-alkaline phosphatase technique with levamisole as blocking agent. Cells are counterstained with haematoxylin to visualise their nuclear morphology.

\section{Quality control}

Because haematopoietic cells can sometimes be stained by anticytokeratin antibodies, ${ }^{5}$ rigorous internal and external quality control procedures must be applied.

\section{Internal controls}

Before the technique can be used in clinical practice, it should first be evaluated on bone marrow samples from patients without cancer (orthopaedic surgery specimens, for example) in order to validate its specificity. The technique must also be calibrated (primary antibodies and revelation system dilutions) using breast cancer cell lines such as MCF7 or SKBR3 at different dilutions, spiked into mononuclear cells from patients without breast cancer. All specimens from breast cancer patients must also be systematically examined in parallel with controls, consisting of slides stained with isotype-matched immunoglobulin.

\section{External controls}

Ring experiments are highly recommended to improve the between-centre reproducibility of bone marrow analysis.

\section{Analysis of cell preparations}

Morphological analysis has been clearly shown to improve the specificity of DTC identification and is highly recommended, but optimal separation of DTC from cytokeratin-positive haematopoietic or non-haematopoietic cells remains challenging, as it is often difficult to detect single DTC in mononuclear cell fractions from BM. Manual screening of $2-3 \times 10^{6}$ cells and $2-3 \times 10^{6}$ negative control cells using light microscopy is performed by an experienced observer. Morphological analysis of cytokeratin-positive cells is based on consensus criteria. ${ }^{36}$ The read-out of positive cells should be controlled by at least two independent observers. The screening of large volumes of material by immunocytochemical techniques can be timeconsuming; automated image-analysis systems can be used. In a European interlaboratory testing of well-known procedures for immunocytochemical detection of epithelial cells in bone marrow, the MDS1 from Applied Imaging screening sensitivity was similar to manual screening, while ACIS from Chromavision detected fewer cells. ${ }^{7}$

Standardised interpretation according to European guidelines ${ }^{367}$ is required to improve the specificity of DTC detection.

- Samples are classified into two categories: positive or negative.

- Positive samples are those with cytokeratin-positive cells with disseminated tumour cell morphology. The number of cells should be indicated.

- Negative samples are those with no positive immunocytochemical stained cells or cytokeratin-positive cells without disseminated tumour cell morphology (e.g. haematopoietic cells, squamous cells).
- All cytokeratin-positive cells should be classified as disseminated tumour cells, i.e. cytokeratin-positive cells with disseminated tumour cell morphology or cytokeratin-positive cells.

The morphological features of DTC are:

- The presence of cell clusters (fig 1A).

- Large cell size with a clearly enlarged nuclear size and a high nuclear-to-cytoplasmic ratio (fig 1B), and strong or irregular cytoplasmic staining for cytokeratin.

- Cytokeratin filaments can be seen.

- Staining partially covers the nucleus. A large nucleolus can be seen and the nucleus is often granular or stippled (fig 1B).

Some cytokeratin cells are clearly recognised as haematopoietic or squamous cells (fig 1C).

According to morphological classification guidelines, positivity rates are about $13-15 \%,{ }^{58}$ in contrast with the $30-35 \%$ positivity rates reported in studies based exclusively on cytokeratin positivity without morphological analysis. ${ }^{1}$ Notably molecular analysis of cytokeratin-positive BM cells has shown that these cells may be malignant. ${ }^{10}$ Clinical studies $^{11} 12$ have also demonstrated the prognostic value of cytokeratin-positive BM cells not classified as DTC and cytokeratin-positive cells.

In order to increase the number of epithelial cells found in the bone marrow, several workers have used immunomagnetic methods of selection (IMS). Available techniques use antibodies, linked to small paramagnetic beads or colloids of $1 \mathrm{~nm}$ (ferrofluids), with an affinity for specific cells. The cells can then be selected with a powerful magnet. Beads are available linked to antiepithelial antibodies for positive selection, like epithelial cell adhesion molecule (Ep-CAM), or linked to a monoclonal antibody directed against CD45 for negative selection of leucocytes. ${ }^{13}$ The use of negative IMS increased the frequency of positive BM in a large series from Norway but did not improve the prognostic value of this detection. ${ }^{14}$

Some studies have assessed DTC detection by using molecular biology techniques such as real-time quantitative PCR determination with several markers: CK19, MUC1, ${ }^{15}$ urokinase-type plasminogen activator receptor (UPAR), EpCAM $^{16}$ and mammaglobin. ${ }^{17}$ This detection should be more sensitive (1 tumour cell in $10^{7}$ mononuclear cells) and more effective. However, using PCR to detect DTC raises two problems: firstly, the real problem of identifying appropriate sensitive and specific markers; and secondly, a problem of quantification. As no specific markers are available to detect DTC in BM, it is therefore not recommended to detect DTC in clinical trials by RT PCR alone without associated immunocytochemical detection.

\section{Prospects}

DTC detection using more specific markers should improve the clinical relevance and reproducibility of this new parameter. One possibility would be to use markers that characterise each subtype of breast carcinoma, such as HER2, as this status is generally maintained in early metastasis such as DTC. ${ }^{9}{ }^{18}$ EGFR overexpression could also be promising in the basal-like subgroup.

\section{CLINICAL SIGNIFICANCE OF DTC}

Several studies over the last two decades have assessed the prevalence and prognostic value of micrometastatic dissemination of breast cancer cells in bone marrow. These studies estimated that $12-45 \%$ of patients with primary operable breast 



Figure 1 Examples of A45/BB3-positive disseminated tumour cells (DTC) and haematopoietic cells. (A) Clusters of DTC. (B) Isolated DTC. The cell is taller than other surrounding cells, with a high nuclear/cytoplasmic ratio; it shows strong and irregular cytoplasmic staining for cytokeratin. (C) Haematopoietic cell.

cancer could have tumour cells in the bone marrow as determined by immunocytochemistry. ${ }^{1}{ }^{1}{ }^{12}$ 19-22 Table 1 summarises the major studies using immunocytochemical detection of DTC in BM. In a pooled analysis of nine studies comprising 4703 patients with stage I, II or III breast cancer, the presence of micrometastases at diagnosis was detected in $30.6 \%$ of patients. With a follow-up of 10 years, this analysis demonstrated that DTC in BM at the time of the initial diagnosis of breast cancer was a significant and independent prognostic factor with respect to poor overall survival and breast cancer-specific survival (univariate mortality ratios: 2.15 and 2.44, respectively; $\mathrm{p}<0.001$ for both outcomes) and poor disease-free survival and distant disease-free survival during the 10-year observation period (incidence rate ratios: 2.13 and 2.33, respectively; $p<0.001$ for both outcomes). This evidence could be sufficient to include DTC analysis in the routine staging of primary breast cancer. However, technical issues remain controversial and bone marrow aspiration is not considered to be a convenient procedure for patients.

Peripheral blood would be an ideal source for the detection of tumoural cells, and sequential peripheral blood analyses are more acceptable. Depending on the detection technique used, circulating tumoural cells (CTC) were revealed in $50-100 \%$ of patients with metastatic breast cancer. ${ }^{23}$ Even in patients with no clinical signs of overt metastases, however, detection rates range from $10 \%$ to $60 \% .{ }^{24}$ Detection of CTC with the CellSearch system (Veridex, Warren, New Jersey, USA), which detects CTC using Ep-CAM coated beads for enrichment followed pan CK staining, provided significant prognostic information before and also early (4 weeks) after initiation of chemotherapy in patients with metastatic breast cancer. ${ }^{25}$ CTC had superior and independent prognostic value of tumour burden and disease phenotype. ${ }^{26}$ In contrast to patients with metastatic disease, and despite promising results, ${ }^{27}$ the prognostic relevance of CTC in the blood of patients with early-stage disease without overt metastasis needs to be demonstrated in prospective multicenter studies. $^{28}$

It is not clear if CTC measurements could replace the examination of bone marrow. Two immunocytochemical studies demonstrated statistically significant correlations between DTC detection in BM and CTC in blood, but BM was more frequently positive than blood. ${ }^{29}{ }^{30}$ Recently, Benoy et al found that real-time RT-PCR based detection of DTC in BM had superior significance to CTC measurements in blood. ${ }^{31}$ In addition, Wiedswang et al, with an ICC assay, showed that BM but not blood analyses provided prognostic information. ${ }^{32}$ These finding do not support an exchange of DTC in BM with CTC from blood.

An important potential application for DTC detection is the monitoring of therapeutic efficacy in the adjuvant setting which can currently only be assessed retrospectively in large-scale clinical trials after an observation period of at least 5 years. Persistence of DTC in BM some years after diagnosis and initial therapy is still an indicator of subsequent systemic treatment failure. ${ }^{33-35}$ Persistence or disappearance of DTC after systemic treatment could therefore be used as a surrogate marker of treatment response. ${ }^{36}$ Studies have shown that adjuvant chemotherapy has no effect on the elimination of single dormant tumour cells in the BM of high-risk breast cancer patients. ${ }^{37} 38$ This emphasises the need to develop therapeutic agents that are active on non-proliferating cells. Bisphosphonates have been used to eliminate tumour cells in BM persisting after adjuvant therapy. The most promising agents are antibodies such as edrecolomab directed against EpCAM $^{39}$ or trastuzumab directed against HER2. ${ }^{40}$ Large-scale prospective clinical trials must now be conducted to determine whether eradication of DTC in BM after systemic therapy results in longer survival.

\section{BIOLOGICAL AND CLINICAL OUESTIONS RAISED BY MICROMETASTATIC CELLS}

The micrometastasis phenomenon is usually described as "tumour cell dormancy", ${ }^{41}$ added as a late step of the metastatic cascade. ${ }^{42}$ Although dormancy regulation is a key element of micrometastasis biology, micrometastatic cells can be assumed to be more than just dormant cancer cells; they could help us to understand certain aspects of metastasis biology. The main clinical and biological questions raised by the micrometastatic process and the current answers to these questions, are described below.

\section{How and when does micrometastasis occur?}

The main clinical study reported that cytokeratin or mucin positive BM cells are associated with tumour size, grade, negative hormone receptors and lymph node metastases. ${ }^{1}$ Using a more stringent detection technique, we did not reproduce any of these results, ${ }^{8}$ although they have been confirmed by others. ${ }^{43}$ This might suggest that micrometastatic dissemination occurs in highly proliferative tumours, when a critical tumour size has been reached. However, DTC may be found at earlier stages of primary tumour development, and comparative genomic hybridisation analyses of disseminated 
Table 1 Major clinical studies of the prognostic value of disseminated tumour cells (DTC) detection in bone marrow (BM) by immunocytochemistry and prognostic value on disease and overall survival (univariate and multivariate analysis)

\begin{tabular}{|c|c|c|c|c|c|c|c|c|c|}
\hline \multirow[b]{2}{*}{ Reference } & \multirow[b]{2}{*}{ Sampling } & \multirow[b]{2}{*}{ Marker } & \multirow[b]{2}{*}{ No. patients } & \multirow{2}{*}{$\begin{array}{l}\text { Detection } \\
\text { rate }(\%)\end{array}$} & \multirow{2}{*}{$\begin{array}{l}\text { Follow-up } \\
\text { (mth) }\end{array}$} & \multicolumn{2}{|c|}{ Disease free survival } & \multicolumn{2}{|c|}{ Overall survival } \\
\hline & & & & & & Univ & Multiv & Univ & Multiv \\
\hline Redding $1983^{79}$ & Smear & MUC & 110 & 28 & & NA & NA & NA & NA \\
\hline Manegold $1988^{80}$ & $\begin{array}{l}\text { Biopsy } \\
\text { Smear }\end{array}$ & CK/PKK1 & 50 & 8 & & NA & NA & NA & NA \\
\hline Landys $1998^{81}$ & Biopsy & CK/AE1-AE3, KL1, CAM 5-2 & 128 & 19 & 240 & NA & NA & Yes & NA \\
\hline Salvadori $1990^{82}$ & Biopsy & $\mathrm{CK} / \mathrm{MBr} 1$ & 121 & 16.5 & 48 & No & No & NA & NA \\
\hline Mathieu $1990^{83}$ & Biopsy & $\begin{array}{l}\text { MUC/EMA, HMFG2 } \\
\text { CK/KL1, AE1-AE3, CAM5-2 }\end{array}$ & 93 & 1 & & No & No & No & No \\
\hline Kirk $1990^{84}$ & Smear & $\begin{array}{l}\text { MUC/anti-milk fat globulin } \\
\text { LICR.LON.M8.4 }\end{array}$ & 25 & 48 & 34 & No & NA & NA & NA \\
\hline Singletary $1991^{85}$ & Smear & $\begin{array}{l}\text { CK/AE1, AE3, MAK-6 } \\
\text { MUC/113F1, 260F9, } 317 \mathrm{G} 5\end{array}$ & 71 & 38 & 11 & No & No & No & No \\
\hline Cote $1991^{86}$ & Smear & $\begin{array}{l}\text { MUC/C26, T16 } \\
\text { CK/AE-1 }\end{array}$ & 49 & 36.7 & 30 & Yes & Yes & NA & $\mathrm{Na}$ \\
\hline Schlimok $1992^{87}$ & Cytospin & CK18/CK2 & 187 & 18 & 39 & Yes & Yes & NA & NA \\
\hline Harbeck $1994^{88}$ & Smear & $\begin{array}{l}\text { CK } \\
\text { MUC/EMA }\end{array}$ & 100 & 38 & 34 & Yes & Yes & No & Yes \\
\hline Ménard $1994^{89}$ & Cytospin & $\begin{array}{l}\text { CK/MBr1, MBr8, CK18/CK2, } \\
\text { MUC1 }\end{array}$ & 197 & 31 & NA & NA & NA & NA & NA \\
\hline Molino $1997^{90}$ & Cytospin & $\begin{array}{l}\text { CK/MBr1, MBr8, MoV8, Mov16 } \\
\text { MluC1 }\end{array}$ & 109 & 31 & 36 & No & No & No & No \\
\hline Funke $1996^{91}$ & Cytospin & CK18/CK2 & 234 & 38 & NA & NA & NA & NA & NA \\
\hline Diel $1996^{9293}$ & Smear & MUC/TAG12 (2E11) & 727 & 43.3 & 78 & Yes & Yes & Yes & Yes \\
\hline Mansi $1999^{12} 94$ & Smear & EMA & 350 & 25.4 & 150 & Yes & No & Yes & No \\
\hline Lyda $2000^{95}$ & Biopsy & CK/AE1-AE3, 35ßH11 CAM 5-2 & 54 & 31 & 38 & Yes & NA & NA & NA \\
\hline Untch $1999^{96}$ & Cytospin & CK18/CK2 & 581 & 28 & & No & No & No & No \\
\hline Braun $2000^{11}$ & Cytospin & СК/СК8,18,19 (A45 B/B3) & 552 & 36 & 36 & Yes & Yes & Yes & Yes \\
\hline Gerber $2001^{20}$ & Cytospin & СК/СK8,18,19 (5D3) & 554 & 37 & 54 & Yes & Yes & Yes & Yes \\
\hline Gebauer2001 21 & Smear & CK, MUC/EMA & 396 & 42 & 75 & Yes & Yes & Yes & Yes \\
\hline Kasimir-Bauer $2001^{97}$ & Cytospin & СК/CK8,18,19 (A45 B/B3) & 128 & 34 & 24 & NA & NA & NA & NA \\
\hline Naume $2004^{5}$ & Cytospin & CK/AE1/AE3 & 819 & 13 & 49 & Yes & Yes & Yes & Yes \\
\hline Braun $2005^{1}$ & Various & Various & 4703 & 30.6 & 63 & Yes & Yes & Yes & Yes \\
\hline Bidard $2007^{8}$ & Cytospin & CK/CK8,18,19 (A45 B/B3) & 621 & 15 & 50 & Yes & Yes & Yes & Yes \\
\hline
\end{tabular}

CK, cytokeratin; Muc, mucin; EMA, epithelial membrane antigen; NA, not available.

cancer cells were in favour of early dissemination of breast cancer cells to the BM. ${ }^{10}{ }^{44}$ Supervised transcriptomic profiling of 19 primary tumours has been reported, ${ }^{45}$ but this micrometastasis-associated profile has not been further validated by independent unsupervised analysis. No pathological studies have demonstrated a link between micrometastasis detection and the recently described breast cancer subtypes. ${ }^{46}$ Therefore, although BM DTC may appear early, it is unknown whether they correspond to a genetically homogeneous subgroup of primary cancers.

Among the mechanisms of breast cancer cell dissemination to the $\mathrm{BM}$, bone and bone marrow homing of cancer cells may depend on similar molecular determinants, especially the SDF1/ CXCR4 axis. ${ }^{47}{ }^{48}$ CXCR4 is a G protein-coupled receptor, ${ }^{49}$ which plays a role in the chemotaxis of breast cancer cells. This cellular response is attributed to activation of the PI3K/PTEN/AKT/ mTOR signalling pathway, ${ }^{49}$ rather than the MAP/ERK pathway. ${ }^{50}{ }^{51}$ CXCR4 expression in 142 primary breast cancers has been shown to be associated with the detection of BM DTC. ${ }^{52}$ This pathway might be responsible for early dissemination of breast cancers, as circulating cancer cells detected in the blood are also characterised by activation of PI3K.$^{53}$ Epithelial-mesenchymal transition and primary tumour microvessel density may also be involved in the onset of DTC. ${ }^{55}$ Finally, the molecular determinants responsible for the establishment of BM DTC are not clearly understood at the present time. BM DTC could be a useful tool to assess the efficiency of the entire cancer cell migration process and should be analysed together with circulating tumour cells in blood and primary breast tumours.

\section{Are micrometastatic cells metastatic progenitors?}

Bone marrow is the host organ of breast cancer metastases, which is the most accessible tissue for analysis, as liquid aspirates can be performed under local anaesthesia or during primary surgery. It is of critical importance to determine whether DTC are (or are not) the metastatic progenitors of bone and/or distant non-bone metastasis. A negative answer would limit the accuracy of bone marrow DTC as a biological model, a target for adjuvant treatment and a marker of response. Paget ${ }^{56}$ was the first to describe the non-random growth of metastases, and the sustaining molecular determinants of cancer cell homing have been recently characterised. ${ }^{52} 5758$ If BM DTC are derived from the specific spread of a few tumour subclones into flat bones, their ability to recirculate to other organs would be somehow limited. Consequently, their detection would be linked to an increase of bone metastasis at primary relapse in patients, but not to that of other metastatic sites. Micrometastases retained their clonogenic and tumourigenic capacities in many biological reports. ${ }^{59-61}$ Clinical studies have reported a link between BM DTC and the onset of bone metastasis, ${ }^{18} 43$ strongly supporting the idea of local growth of DTC into macrometastases. 
Surprisingly, other organs (especially the liver) also appear to be a favourite site of breast cancer relapse. ${ }^{83}$ However, the CXCR4 receptor is reported to be involved in homing to both sites, ${ }^{52}$ but the current literature does not provide strong evidence for a common pool of genes responsible for coupled homing to bone marrow (or flat bones) and liver. The other alternative is that bone marrow may act as a long-term reservoir of tumour cells, which can recirculate to other distant organs before growing into metastases. ${ }^{62}$ The high genetic heterogeneity ${ }^{63}$ of $\mathrm{BM}$ micrometastatic cells might be responsible for recirculation of some cancer seeds from the bone marrow to different host organs. However, no biological or clinical study has directly reported such a process for BM DTC and there is currently no direct evidence suggesting that they are responsible for the late growth of lung of liver metastases. On the contrary, many biological models have reported that the micrometastatic dissemination of mammary tumours occurs in most of the target organs of metastases ${ }^{64-66}$ and is not restricted to a unique reservoir in the bone marrow. Also, 40 months after the surgical treatment of non-metastatic breast cancer, the detection of circulating cancer cells in the peripheral blood was not correlated with the presence of bone marrow DTC. ${ }^{32}$ Finally, the local growth of some BM DTC into bone macrometastasis is clinically and biologically rational. In the case of distant nonbone or local relapses predicted by BM DTC, ${ }^{8}$ these cells mostly appear as a marker of a body-wide dissemination of invasive cancer cells rather than the body's only long-term reservoir of disseminated cancer cells.

\section{How is micrometastatic dormancy regulated?}

Dormancy may be induced in disseminated cancer cells by lack of the primary tumour microenvironment (absence of stimulating growth factors, ${ }^{67}$ presence of growth-inhibiting cytokin ${ }^{68}$ ). Metastatic growth may be a rare and stochastic event secondary to selection and mutations of dormant cancer cells. ${ }^{69}$ The end of dormancy may also be induced by any change of the microenvironmental homoeostasis, such as the presence of growth factors or an immune response. ${ }^{70}$ Many groups investigating the mechanisms of dormancy have reported the role of integrin $\alpha 5 \beta 1$ in regulating breast cancer cell dormancy. This integrin is activated by the urokinase-type plasminogen activator receptor (uPAR). Its main signalling pathway is the FAK/Src and ERK pathway to promote cell mobility; inhibition of this integrin leads to cancer cell dormancy in biological models. ${ }^{71} 72$ Integrin $\alpha 5 \beta 1$ appears to be necessary, via the PI3K/ AKT pathway, for the survival of dormant cancer cells.$^{68}$ uPAR expression by BM DTC has also been linked to a poorer prognosis in a population of micrometastatic patients. ${ }^{16}$

Regulation of cancer cell dormancy may also involve genes and other processes, which regulate primary tumour growth. Finally, most BM DTC-positive patients never relapse, while others experience dramatic metastatic progression. These different outcomes cannot be explained at the present time and require further investigation.

\section{Micrometastasis and cancer stem cells}

The role of cancer stem cells in the establishment of metastasis remains controversial in many theoretical proposals and reviews. $^{73-76}$ Experimentally, CD44+/CD24-/low cancer cells, a phenotype associated with a stem cell pattern, exhibit an invasive phenotype, ${ }^{77}{ }^{78}$ which is a prerequisite to metastasis. In a report on 50 cases, most BM micrometastatic breast cancer cells exhibited a stem cell-like immunohistochemical phenotype. ${ }^{76}$

\section{Take-home messages}

- Immunocytochemical detection of disseminated tumour cells in the bone marrow of primary breast cancer patients at surgery is an independent prognostic factor of poor outcome.

- Accurate identification of disseminated tumour cells (DTC) in bone marrow must be based on standardised methodologies and procedures.

- Prognostic value of circulating tumour cells (CTC) detection in peripheral blood is demonstrated in patients with metastatic disease but remains to be substantiated at early stage.

- DTC and CTC detection should be used in stratification and monitoring of therapeutic efficacy.

- Research on DTC could help in understanding tumour dormancy and identifying metastatic stem cells.

\section{CONCLUSION}

BM DTC detection is a very promising prognostic parameter that will improve clinical management of patients with breast cancer in the near future. DTC detection must now be implemented in clinical trials to improve treatment selection. DTC specificity is considerably increased by histological examination according to international guidelines and must be submitted to high-level quality control. The future development of targeted therapies against BM DTC should significantly improve patient outcome and raises interesting new biological questions that should further our understanding of breast cancer carcinogenesis.

Competing interests: None declared.

\section{REFERENCES}

1. Braun S, Vogl FD, Naume B, et al. A pooled analysis of bone marrow micrometastasis in breast cancer. N Engl J Med 2005;353:793-802.

2. Harris L, Fritsche H, Mennel R, et al. American Society of Clinical Oncology 2007 update of recommendations for the use of tumor markers in breast cancer. $J$ Clin Oncol 2007;25:5287-312.

3. Fehm T, Braun S, Muller V, et al. A concept for the standardized detection of disseminated tumor cells in bone marrow from patients with primary breast cancer and its clinical implementation. Cancer 2006;107:885-92.

4. Wiedswang G, Borgen E, Karesen R, et al. Detection of isolated tumor cells in BM from breast-cancer patients: significance of anterior and posterior iliac crest aspirations and the number of mononuclear cells analyzed. Cytotherapy 2003:5:40-5.

5. Naume B, Wiedswang G, Borgen E, et al. The prognostic value of isolated tumor cells in bone marrow in breast cancer patients: evaluation of morphological categories and the number of clinically significant cells. Clin Cancer Res 2004;10:3091-7.

6. Borgen E, Naume B, Nesland JM, et al. Standardization of the immunocytochemical detection of cancer cells in BM and blood. I: Establishment of objective criteria for the evaluation of immunostained cells. The European ISHAGE Working Group for Standardization of Tumor Cell Detection. Cytotherapy 1999;1:377-88.

7. Borgen E, Pantel K, Schlimok G, et al. A European interlaboratory testing of three well-known procedures for immunocytochemical detection of epithelial cells in bone marrow. Results from analysis of normal bone marrow. Cytometry B Clin Cytom 2006;70:400-9.

8. Bidard FC, Vincent-Salomon A, Gomme S, et al. Bone marrow micrometastasis are a powerful prognostic factor in stage I to III breast cancer patients. Abstract S460. AACR Annual Meeting, Proceedings, 14-18 April 2007.

9. Schardt JA, Meyer M, Hartmann $\mathrm{CH}$, et al. Genomic analysis of single cytokeratinpositive cells from bone marrow reveals early mutational events in breast cancer. Cancer Cell 2005;8:227-39.

10. Schmidt-Kittler $\mathbf{0}$, Ragg T, Daskalakis A, et al. From latent disseminated cells to overt metastasis: genetic analysis of systemic breast cancer progression. Proc Nat/ Acad Sci USA 2003;100:7737-42.

11. Braun S, Pantel K, Muller $P$, et al. Cytokeratin-positive cells in the bone marrow and survival of patients with stage I, II, or III breast cancer. N Engl J Med 2000;342:525-33.

12. Mansi JL, Gogas H, Bliss JM, et al. Outcome of primary-breast-cancer patients with micrometastases: a long-term follow-up study. Lancet 1999;354:197-202.

13. Ring A, Smith IE, Dowsett M. Circulating tumour cells in breast cancer. Lancet Oncol 2004:5:79-88. 
14. Naume B, Borgen E, Kvalheim G, et al. Detection of isolated tumor cells in bone marrow in early-stage breast carcinoma patients: comparison with preoperative clinical parameters and primary tumor characteristics. Clin Cancer Res 2001;7:4122-9.

15. de Crémoux $\mathbf{P}$, Extra JM, Denis MG, et al. Detection of MUC1-expressing mammary carcinoma cells in the peripheral blood of breast cancer patients by real-time polymerase chain reaction. Clin Cancer Res 2000;6:3117-22.

16. Pierga JY, Bonneton C, Magdelenat $\mathrm{H}$, et al. Real-time quantitative PCR determination of urokinase-type plasminogen activator receptor (UPAR) expression of isolated micrometastatic cells from bone marrow of breast cancer patients. Int J Cancer 2005;114:291-8.

17. Ferrucci PF, Rabascio C, Gigli F, et al. A new comprehensive gene expression panel to study tumor micrometastasis in patients with high-risk breast cancer. Int J Oncol 2007;30:955-62.

18. Vincent-Salomon A, Pierga JY, Couturier J, et al. HER2 status of bone marrow micrometastasis and their corresponding primary tumours in a pilot study of 27 cases: a possible tool for anti-HER2 therapy management? Br J Cancer 2007;96:654-9.

19. Slade MJ, Coombes RC. The clinical significance of disseminated tumor cells in breast cancer. Nat Clin Pract Oncol 2007;4:30-41.

20. Gerber B, Krause A, Muller H, et al. Simultaneous immunohistochemical detection of tumor cells in lymph nodes and bone marrow aspirates in breast cancer and its correlation with other prognostic factors. J Clin Oncol 2001;19:960-71.

21. Gebauer G, Fehm T, Merkle E, et al. Epithelial cells in bone marrow of breast cancer patients at time of primary surgery: clinical outcome during long-term follow-up. J Clin Oncol 2001;19:3669-74.

22. Braun S, Pantel K. Clinical significance of occult metastatic cells in bone marrow of breast cancer patients. Oncologist 2001;6:125-32.

23. Zach 0, Lutz D. Tumor cell detection in peripheral blood and bone marrow. Curr Opin Oncol 2006;18:48-56

24. Muller V, Hayes DF, Pantel K. Recent translational research: circulating tumor cells in breast cancer patients. Breast Cancer Res 2006;8:110.

25. Cristofanilli M, Budd GT, Ellis MJ, et al. Circulating tumor cells, disease progression, and survival in metastatic breast cancer. N Engl J Med 2004;351:781-91.

26. Cristofanilli $\mathbf{M}$, Broglio KR, Guarneri V, et al. Circulating tumor cells in metastatic breast cancer: biologic staging beyond tumor burden. Clin Breast Cancer 2007; 7:471-9.

27. Ignatiadis $\mathbf{M}$, Xenidis $\mathbf{N}$, Perraki $\mathbf{M}$, et al. Different prognostic value of cytokeratin-19 mRNA-positive circulating tumor cells according to estrogen receptor and HER2 status in early-stage breast cancer. J Clin Oncol 2007;25:5194-202.

28. Cristofanilli M, Mendelsohn J. Circulating tumor cells in breast cancer: advanced tools for "tailored" therapy? Proc Natl Acad Sci USA 2006;103:17073-4.

29. Muller V, Stahmann N, Riethdorf S, et al. Circulating tumor cells in breast cancer: correlation to bone marrow micrometastases, heterogeneous response to systemic therapy and low proliferative activity. Clin Cancer Res 2005;11:3678-85.

30. Pierga JY, Bonneton C, Vincent-Salomon A, et al. Clinical significance of immunocytochemical detection of tumor cells using digital microscopy in peripheral blood and bone marrow of breast cancer patients. Clin Cancer Res 2004;10:1392-400.

31. Benoy IH, Elst H, Philips M, et al. Prognostic significance of disseminated tumor cells as detected by quantitative real-time reverse-transcriptase polymerase chain reaction in patients with breast cancer. Clin Breast Cancer 2006;7:146-52.

32. Wiedswang G, Borgen E, Schirmer $\mathrm{C}$, et al. Comparison of the clinical significance of occult tumor cells in blood and bone marrow in breast cancer. Int $J$ Cancer 2005;118:2013-9.

33. Janni W, Rack B, Schindlbeck C, et al. The persistence of isolated tumor cells in bone marrow from patients with breast carcinoma predicts an increased risk for recurrence. Cancer 2005;103:884-91.

34. Wiedswang G, Borgen E, Karesen $\mathrm{R}$, et al. Isolated tumor cells in bone marrow three years after diagnosis in disease-free breast cancer patients predict unfavorable clinical outcome. Clin Cancer Res 2004;10:5342-8.

35. Slade MJ, Singh A, Smith BM, et al. Persistence of bone marrow micrometastases in patients receiving adjuvant therapy for breast cancer: results at 4 years. Int $J$ Cancer 2005:114:94-100.

36. Lacroix M. Significance, detection and markers of disseminated breast cancer cells. Endocr Relat Cancer 2006;13:1033-67.

37. Quintela-Fandino M, Lopez JM, Hitt R, et al. Breast cancer-specific mRNA transcripts presence in peripheral blood after adjuvant chemotherapy predicts poor survival among high-risk breast cancer patients treated with high-dose chemotherapy with peripheral blood stem cell support. J Clin Oncol 2006;24:3611-8.

38. Braun S, Kentenich C, Janni W, et al. Lack of effect of adjuvant chemotherapy on the elimination of single dormant tumor cells in bone marrow of high-risk breast cancer patients. J Clin Oncol 2000;18:80-6.

39. Braun S, Hepp F, Kentenich CR, et al. Monoclonal antibody therapy with edrecolomab in breast cancer patients: monitoring of elimination of disseminated cytokeratin-positive tumor cells in bone marrow. Clin Cancer Res 1999;5:3999-4004.

40. Bozionellou V, Mavroudis D, Perraki M, et al. Trastuzumab administration can effectively target chemotherapy-resistant cytokeratin-19 messenger RNA-positive tumor cells in the peripheral blood and bone marrow of patients with breast cancer. Clin Cancer Res 2004;10:8185-94.

41. Allan AL, Vantyghem SA, Tuck AB, et al. Tumor dormancy and cancer stem cells: implications for the biology and treatment of breast cancer metastasis. Breast Dis 2006;26:87-98

42. Townson JL, Chambers AF. Dormancy of solitary metastatic cells. Cell Cycle 2006:5:1744-50.
43. Wiedswang G, Borgen E, Karesen $\mathrm{R}$, et al. Detection of isolated tumor cells in bone marrow is an independent prognostic factor in breast cancer. J Clin Oncol 2003:21:3469-78.

44. Gangnus R, Langer S, Breit E, et al. Genomic profiling of viable and proliferative micrometastatic cells from early-stage breast cancer patients. Clin Cancer Res 2004;10:3457-64.

45. Kollermann J, Muller M, Goessl C, et al. Methylation-specific PCR for DNA-based detection of occult tumor cells in lymph nodes of prostate cancer patients. Eur Urol 2003; 44:533-8

46. Perou CM, Sorlie T, Eisen MB, et al. Molecular portraits of human breast tumours Nature 2000;406:747-52.

47. Wang J, Loberg R, Taichman RS. The pivotal role of CXCL12 (SDF-1)/CXCR4 axis in bone metastasis. Cancer Metastasis Rev 2006;25:573-87.

48. Kaifi JT, Yekebas EF, Schurr P, et al. Tumor-cell homing to lymph nodes and bone marrow and CXCR4 expression in esophageal cancer. J Natl Cancer Inst 2005;97:1840-7.

49. Holland JD, Kochetkova M, Akekawatchai C, et al. Differential functional activation of chemokine receptor CXCR4 is mediated by $\mathrm{G}$ proteins in breast cancer cells. Cancer Res 2006;66:4117-24.

50. Peng SB, Peek V, Zhai Y, et al. Akt activation, but not extracellular signal-regulated kinase activation, is required for SDF-1alpha/CXCR4-mediated migration of epitheloid carcinoma cells. Mol Cancer Res 2005;3:227-36

51. Sun Y, Cheng Z, Ma L, et al. Beta-arrestin2 is critically involved in CXCR4-mediated chemotaxis, and this is mediated by its enhancement of p38 MAPK activation. J Biol Chem 2002;277:49212-9.

52. Andre F, Cabioglu N, Assi $\mathrm{H}$, et al. Expression of chemokine receptors predicts the site of metastatic relapse in patients with axillary node positive primary breast cancer. Ann Oncol 2006;17:945-51

53. Kallergi G, Mavroudis D, Georgoulias V, et al. Phosphorylation of FAK, PI-3K, and impaired actin organization in CK-positive micrometastatic breast cancer cells. $\mathrm{Mol}$ Med 2007:13:79-88.

54. Willipinski-Stapelfeldt B, Riethdorf S, Assmann V, et al. Changes in cytoskeletal protein composition indicative of an epithelial-mesenchymal transition in human micrometastatic and primary breast carcinoma cells. Clin Cancer Res 2005:11:8006-14.

55. Benoy IH, Salgado R, Elst H, et al. Relative microvessel area of the primary tumour, and not lymph node status, predicts the presence of bone marrow micrometastases detected by reverse transcriptase polymerase chain reaction in patients with clinically non-metastatic breast cancer. Breast Cancer Res 2005; 7:R210-9.

56. Paget S. The distribution of secondary growths in cancer of the breast. 1889. Cancer Metastasis Rev 1989;8:98-101.

57. Minn AJ, Gupta GP, Siegel PM, et al. Genes that mediate breast cancer metastasis to lung. Nature 2005:436:518-24.

58. Kang Y, Siegel PM, Shu W, et al. A multigenic program mediating breast cancer metastasis to bone. Cancer Cell 2003:3:537-49.

59. Suzuki M, Mose ES, Montel V, et al. Dormant cancer cells retrieved from metastasis-free organs regain tumorigenic and metastatic potency. Am J Pathol 2006;169:673-81.

60. Putz E, Witter K, Offner S, et al. Phenotypic characteristics of cell lines derived from disseminated cancer cells in bone marrow of patients with solid epithelial tumors: establishment of working models for human micrometastases. Cancer Res 1999;59:241-8

61. Pierga JY, Bonneton C, Magdelenat $\mathrm{H}$, et al. Clinical significance of proliferative potential of occult metastatic cells in bone marrow of patients with breast cancer Br J Cancer 2003;89:539-45.

62. Meng S, Tripathy D, Frenkel EP, et al. Circulating tumor cells in patients with breast cancer dormancy. Clin Cancer Res 2004;10:8152-62.

63. Klein CA, Blankenstein TJ, Schmidt-Kittler 0, et al. Genetic heterogeneity of single disseminated tumour cells in minimal residual cancer. Lancet 2002;360:683-9.

64. Jenkins DE, Hornig YS, Oei Y, et al. Bioluminescent human breast cancer cell lines that permit rapid and sensitive in vivo detection of mammary tumors and multiple metastases in immune deficient mice. Breast Cancer Res 2005:7:R444-54.

65. Kurebayashi J, McLeskey SW, Johnson MD, et al. Quantitative demonstration of spontaneous metastasis by MCF-7 human breast cancer cells cotransfected with fibroblast growth factor 4 and LacZ. Cancer Res 1993;53:2178-87.

66. Naumov GN, MacDonald IC, Weinmeister PM, et al. Persistence of solitary mammary carcinoma cells in a secondary site: a possible contributor to dormancy. Cancer Res 2002:62:2162-8.

67. Yuhas JM, Tarleton AE. Dormancy and spontaneous recurrence of human breast cancer in vitro. Cancer Res 1978;38(11 Pt 1):3584-9.

68. Korah R, Boots M, Wieder R. Integrin alpha5beta1 promotes survival of growtharrested breast cancer cells: an in vitro paradigm for breast cancer dormancy in bone marrow. Cancer Res 2004;64:4514-22.

69. Klein CA, Holzel D. Systemic cancer progression and tumor dormancy: mathematica models meet single cell genomics. Cell Cycle 2006;5:1788-98.

70. Demicheli R, Miceli R, Moliterni A, et al. Breast cancer recurrence dynamics following adjuvant $\mathrm{CMF}$ is consistent with tumor dormancy and mastectomy-driven acceleration of the metastatic process. Ann Oncol 2005:16:1449-57.

71. Aguirre-Ghiso JA. Inhibition of FAK signaling activated by urokinase receptor induces dormancy in human carcinoma cells in vivo. Oncogene 2002;21:2513-24.

72. Aguirre-Ghiso JA, Estrada Y, Liu D, et al. ERK(MAPK) activity as a determinant of tumor growth and dormancy; regulation by p38(SAPK). Cancer Res 2003;63:1684-95.

73. Wicha MS. Cancer stem cells and metastasis: lethal seeds. Clin Cancer Res 2006:12:5606-7. 
74. Vaidya JS. An alternative model of cancer cell growth and metastasis. Int J Surg 2007:5:73-5.

75. Brabletz T, Jung A, Spaderna S, et al. Opinion: migrating cancer stem cells-an integrated concept of malignant tumour progression. Nat Rev Cancer 2005:5:744-9.

76. Balic M, Lin H, Young L, et al. Most early disseminated cancer cells detected in bone marrow of breast cancer patients have a putative breast cancer stem cell phenotype. Clin Cancer Res 2006;12:5615-21.

77. Hill A, McFarlane S, Mulligan K, et al. Cortactin underpins CD44-promoted invasion and adhesion of breast cancer cells to bone marrow endothelial cells. Oncogene 2006;25:6079-91.

78. Sheridan C, Kishimoto H, Fuchs RK, et al. CD44+/CD24 - breast cancer cells exhibit enhanced invasive properties: an early step necessary for metastasis. Breast Cancer Res 2006;8:R59.

79. Redding WH, Coombes RC, Monaghan $\mathrm{P}$, et al. Detection of micrometastases in patients with primary breast cancer. Lancet 1983:2:1271-4.

80. Manegold C, Krempien B, Kaufmann M, et al. The value of bone marrow examination for tumor staging in breast cancer. J Cancer Res Clin Oncol 1988:114:425-8.

81. Landys K, Persson S, Kovarik J, et al. Prognostic value of bone marrow biopsy in operable breast cancer patients at the time of initial diagnosis: results of a 20 -year median follow-up. Breast Cancer Res Treat 1998;49:27-33.

82. Salvadori B, Squicciarini P, Rovini D, et al. Use of monoclonal antibody MBr1 to detect micrometastases in bone marrow specimens of breast cancer patients. Eur J Cancer 1990;26:865-7.

83. Mathieu MC, Friedman S, Bosq J, et al. Immunohistochemical staining of bone marrow biopsies for detection of occult metastasis in breast cancer. Breast Cancer Res Treat 1990;15:21-6.

84. Kirk SJ, Cooper GG, Hoper M, et al. The prognostic significance of marrow micrometastases in women with early breast cancer. Eur J Surg Oncol 1990:16:481-5.

85. Singletary SE, Larry L, Tucker SL, et al. Detection of micrometastatic tumor cells in bone marrow of breast carcinoma patients. J Surg Oncol 1991;47:32-6.

86. Cote RJ, Rosen PP, Lesser ML, et al. Prediction of early relapse in patients with operable breast cancer by detection of occult bone marrow micrometastases. J Clin Oncol 1991:9:1749-56.
87. Schlimok G, Lindemann F, Holzmann K, et al. Prognostic significance of disseminated tumor cells detected in bone marrow of patients with breast and colorectal cancer: a multivariate analysis. Abstract 102. Proc Am Soc Clin Oncol 1992:11

88. Harbeck N, Untch M, Pache L, et al. Tumour cell detection in the bone marrow of breast cancer patients at primary therapy: results of a 3-year median follow-up. Br J Cancer 1994:69:566-71.

89. Menard S, Squicciarini P, Luini A, et al. Immunodetection of bone marrow micrometastases in breast carcinoma patients and its correlation with primary tumour prognostic features. Br J Cancer 1994:69:1126-9.

90. Molino A, Pelosi G, Turazza M, et al. Bone marrow micrometastases in 109 breast cancer patients: correlations with clinical and pathological features and prognosis. Breast Cancer Res Treat 1997:42:23-30.

91. Funke I, Fries S, Rolle M, et al. Comparative analyses of bone marrow micrometastases in breast and gastric cancer. Int J Cancer 1996:65:755-61.

92. Diel IJ, Kaufmann M, Costa SD, et al. Micrometastatic breast cancer cells in bone marrow at primary surgery: prognostic value in comparison with nodal status. J Natl Cancer Inst 1996:88:1652-8.

93. Solomayer EF, Diel IJ, Salanti G, et al. Time independence of the prognostic impac of tumor cell detection in the bone marrow of primary breast cancer patients. Clin Cancer Res 2001;7:4102-8.

94. Berger U, Bettelheim R, Mansi JL, et al. The relationship between micrometastases in the bone marrow, histopathologic features of the primary tumor in breast cancer and prognosis. Am J Clin Pathol 1988;90:1-6.

95. Lyda MH, Tetef M, Carter NH, et al. Keratin immunohistochemistry detects clinically significant metastases in bone marrow biopsy specimens in women with lobular breast carcinoma. Am J Surg Pathol 2000;24:1593-9.

96. Untch M, Kahlert S, Funke l, et al. Detection of cytokeratin (CK) 18 positive cells in the bone marrow (BM) of breast cancer patients-no prediction of bad outcome. (Abstract 2472). Proc Am Soc Clin Oncol 1999;18:693a.

97. Kasimir-Bauer S, Oberhoff C, Sliwinska K, et al. Evaluation of different methods for the detection of minimal residual disease in blood and bone marrow of patients with primary breast cancer: importance for clinical use? Breast Cancer Res Treat 2001:69:123-32.

\section{Invitation to submit images for consideration as a Cover}

Readers are invited to submit images for consideration as a Cover. Cover images are not necessarily linked to a specific paper in that issue but rather are selected for their scientific/clinical interest and aesthetic appeal. We ask that readers only submit those images for which they hold the copyright. Colour images are preferred, should be a minimum of 600 dpi and in CMYK mode. Please submit your images to jclinpath@bmjgroup.com in the first instance. Please also include a clear and concise legend explaining the image. All images will be credited to the appropriate supplier. 